\title{
SELECCIÓN DE UN HONGO FILAMENTOSO ALTAMENTE PRODUCTOR DE AMILASAS PARA SER USADAS EN DETERGENTES BIODEGRADABLES
}

(Selection of filamentous fungus highly producer of amylases to be used in biodegradable detergents)

\author{
Martín Vargas C. ${ }^{1}$, Beatriz Piro M. ${ }^{2}$, Navarro, A. \& Cristina Rubio M. ${ }^{1 *}$ \\ 1 Instituto de Biotecnología. Facultad de Bioquímica, Química y Farmacia. \\ 2Facultad de Medicina. Universidad Nacional de Tucumán. \\ Ayacucho 471 (4000). Tucumán. Argentina. Tel: 54-03814107209; \\ *Autor para correspondencia: mcrubio@fbqf.unt.edu.ar; \\ RECIBIDO:10 de Marzo de 2016 \\ APTOBADO:06 de Junio de 2016
}

LOS AUTORES DECLARAN NO TENER CONFLICTO DE INTERESES

Palabras claves: Amilasas, Aspergillus niger, biodetergentes; hongos

Key words: Amylases; Aspergillus niger, biodetergents; fungus

\section{RESUMEN}

Las amilasas ( $\alpha$-amilasa, EC 3.2.1.1 y glucoamilasa, EC 3.2.1.3) son enzimas extracelulares que hidrolizan el almidón en dextrinas hasta glucosa y tienen gran aplicación industrial, especialmente alimentaria; detergentes y en la producción de alcohol a partir de granos. El objetivo del trabajo es seleccionar un hongo filamentoso que presente alta producción de amilasas con características particulares para ser empleadas en biodetergentes. Se estudiaron los siguientes hongos: Penicillium expansum; P. digitatum; P. islandicum; Aspergillus clavatus; A. niger; A. ochraceus; A. fumigatus; $A$. flavus; A. oryzae; A. nidulans y Geotrichum candidum; Los ensayos se realizaron en un medio de hidrolizado de papa de descarte (variedad Spunta) suplementado con las siguientes sales: $\mathrm{KH}_{2} \mathrm{PO}_{4} 1,0$; $\mathrm{NaNO}_{3} 3,0 ; \mathrm{MgSO}_{4} .7 \mathrm{H}_{2} \mathrm{O} 0,5$, a $\mathrm{pH} 4,0$; se inocu- ló con $2 \times 10^{6}$ conidios $/ \mathrm{mL}$ y se incubaron a $25^{\circ} \mathrm{C}$ en un agitador rotatorio a una velocidad de agitación de $250 \mathrm{rpm}$. Con los extractos enzimáticos parcialmente purificados con $\left(\mathrm{NH}_{4}\right)_{2} \mathrm{SO}_{4}$ al $60 \%$ de saturación, se estudió el efecto del $\mathrm{pH}(2,5 ; 3,5$; $4,0 ; 4,5 ; 5,0 ; 5,5 ; 6,0,7,0$ y 8,0$)$ y la temperatura $\left(20 ; 25 ; 30 ; 35 \mathrm{y} 40^{\circ} \mathrm{C}\right)$. Los resultados mostraron que la máxima producción de enzima (128 U/L) se obtuvo con Aspergillus niger, en las condiciones ensayadas, a las $48 \mathrm{~h}$ de incubación, con alto rendimiento de producto respecto a la biomasa ( $\mathrm{YP} / \mathrm{X}=$ $18,3 \mathrm{U} / \mathrm{g})$ y productividad volumétrica $(\mathrm{Pdv}=2,7$ U/L). El análisis cualitativo de las enzimas del complejo amilolítico de $A$. niger mostró que las amilasas implicadas son $\alpha$-amilasa y glucoamilasa y se caracterizaron por hidrolizar en un tiempo de 3 min. manchas mixtas de almidón y grasas de muestras textiles en un rango de $\mathrm{pH} 4,0$ a 8,0 y de 20 a $40{ }^{\circ} \mathrm{C}$. 


\section{ABSTRACT}

The amylases ( $\alpha$-amylase, EC 3.2.1.1 and glucoamylase, EC 3.2.1.3) are extracellular enzymes that hydrolyze starch into dextrins to glucose and have great application industrial, especially food, detergents and in the production of alcohol from grains. The objective of the study is to select a filamentous fungus that present high production of amylases showing attractive features to be used in biodetergentes. Were studied following fungus: Penicillium expansum; $P$. digitatum; P. islandicum; Aspergillus clavatus; A niger; A. ochraceus; A. fumigatus; A. flavus; A. oryzae; A. nidulans and Geotrichum candidum. The tests were conducted in the medium of hydrolyzed potato discard (variety Spunta) supplemented with the following sales: $\mathrm{KH}_{2} \mathrm{PO}_{4}, 1.0 ; \mathrm{NaNO}_{3}, 3.0$ and $\mathrm{MgSO}_{4} .7 \mathrm{H}_{2} \mathrm{O}, 0.5$, to $\mathrm{pH}$ 4.0. Were inoculated with 2 x 106 conidia/ $\mathrm{mL}$ and incubated at $25^{\circ} \mathrm{C}$ on a rotary Shaker at a speed of $250 \mathrm{rpm}$. With partially purified enzyme extracts with $\left(\mathrm{NH}_{4}\right)_{2} \mathrm{SO}_{4}$ at $60 \%$ of saturation, we studied the effect of $\mathrm{pH}(2.5 ; 3.5 ; 4.0 ; 4.5 ; 5.0 ; 5.5$; $6.0,7.0$ and 8.0$)$ and temperature $(20 ; 25 ; 30 ; 35$, and $40^{\circ} \mathrm{C}$ ). The results showed that the maximum production of enzyme (128 U/L) was obtained with Aspergillus niger, under the conditions tested, at $48 \mathrm{~h}$ of incubation, with high product formation rate with respect to biomass $\left(\mathrm{Y}_{\mathrm{p} / \mathrm{x}}=18.3\right.$ $\mathrm{U} / \mathrm{g})$ and volumetric productivity $(\mathrm{Pdv}=2,7 \mathrm{U} /$ $\mathrm{hL}$ ). The qualitative analysis of the enzymes of the complex amylolític of $A$. niger showed that involved amylases are $\alpha$-amylase and glucoamylase and characterized by hydrolyze in 3 min spots mixed starch and fats of textile samples over a range of $\mathrm{pH} 4.0$ to 8.0 and 20 to $40^{\circ} \mathrm{C}$.

\section{INTRODUCCION}

Las enzimas amilolíticas hidrolizan las moléculas de almidón para obtener azúcares simples como glucosa. En esta familia se encuentran: $\alpha$-amilasa (E.C. 3.2.1.1; $\alpha$-1,4-glucan- 4-glucanohidrolasa), conocida también en el comercio y el ámbito científico como glucogenasa y endoamilasa. Esta endoenzima, libera dextrinas formadas por 7 unidades de glucosa, se la denomina enzima dextrinizante o licuante, debido a la capacidad para disminuir la viscosidad de las soluciones de almidón $(1,2)$ y glucoamilasa (E.C.3.2.1.3) se conoce como amiloglucosidasa y es una $\alpha-1,4-$ D-glucano glucohidrolasa. Esta enzima hidroliza los enlaces $\alpha-1,4-\mathrm{D}$-glucosa, desde el extremo no reductor de la molécula de almidón y los enlaces $\alpha$-1,6-glucosídicos a menor velocidad, por lo cual, el producto final de la acción hidrolítica sobre el almidón es glucosa ( 3 ).

Estas enzimas tienen gran aplicación en la industria alimentaria en la hidrólisis del almidón para la obtención de jarabe de glucosa, maltodextrinas y almidones modificados. En el proceso de panificación, la adición de amilasas tiene por objeto aumentar el valor "panificador" de las harinas, generando un adecuado desprendimiento de $\mathrm{CO}_{2}$ $(4,5)$. En la obtención de cervezas de bajo contenido calórico, las cuales degradan todo el almidón a azúcares fermentables que se convierten en alcohol y $\mathrm{CO}_{2}$, por las levaduras, de esta manera, no se encuentran azúcares libres que aumentan las calorías del producto. En la obtención de alcohol, las amilasas hidrolizan el almidón proveniente de maíz, papas, cebada, yuca, etc., a fin de producir su licuación y sacarificación, antes del proceso de fermentación con las levaduras. En la industria farmacéutica se utilizan en medicamentos para trastornos digestivos (6). En la formulación de detergentes, donde la adición de enzimas como amilasas, proteasas y lipasas tienen la función de actuar sobre las manchas procedentes de alimentos como huevos, vino, salsas, pastas, etc.(7). En la industria textil los hilos se recubren con sustancias adhesivas y gelatinosas denominadas agentes de encolado, para eliminar éstos, antes de utilizar productos químicos, se prefiere el uso de amilasas que hidrolizan el almidón totalmente, sin dañar la tela y a su vez, disminuyen el alto nivel de conta- 
SELECCIÓN DE UN HONGO FILAMENTOSO ALTAMENTE PRODUCTOR DE AMILASAS - Vargas M. et al

minantes químicos que se vierten en las aguas residuales durante el proceso (8).

Las amilasas se encuentran ampliamente distribuidas en tejidos vegetales $(5,9,10)$ y animales (11), pero los microorganismos como bacterias (12), levaduras (13) y hongos filamentosos $(14,15,16)$ son mayormente empleados debido a que presentan mayor concentración de estas enzimas; menor tiempo de cultivo; no influyen factores climáticos. Además un bajo costo asociado al empleo de productos de descarte agrícola, entre ellos, la papa (Solanum tuberosum) que no puede ser comercializada ni sirve para consumo interno, pero contiene un 10 a $20 \%$ de almidón, la cual puede ser empleada como sustrato en procesos biotecnológicos (17). El objetivo del trabajo fue seleccionar un hongo filamentoso que presente alta producción de amilasas con características útiles para ser empleadas como ingrediente en biodetergentes.

\section{MATERIALES Y METODOS}

\section{Selección del hongo con alta producción de amilasa}

Microorganismos: Se estudiaron los siguientes hongos: Penicillium expansum; P. digitatum; P. islandicum; Aspergillus clavatus; A. niger; A. ochraceus; A. fumigatus; A. flavus; A. oryzae; A. nidulans y Geotrichum candidum obtenidos del cepario del Instituto de Biotecnología de la Universidad Nacional de Tucumán.

Mantenimiento de las cepas: Los microorganismos se mantuvieron activos por repiques sucesivos en medio Czapek modificado, que contiene en g/L: glucosa, $10 ; \mathrm{NaNO}_{3}, 3 ; \mathrm{KH}_{2} \mathrm{PO}_{4}, 1 ; \mathrm{MgSO}_{4} .7$ $\mathrm{H}_{2} \mathrm{O}, 0,5 ; \mathrm{KCl}, 0,5 ;$ agar, 15 y se llevó a $\mathrm{pH} 4,5$ con $\mathrm{H}_{2} \mathrm{SO}_{4}(20 \%, \mathrm{v} / \mathrm{v})$. Las cepas se sembraron en tubos con este medio y se incubaron a $25^{\circ} \mathrm{C}$ durante $96 \mathrm{~h}$, posteriormente se mantuvieron a $4^{\circ} \mathrm{C}$ hasta su utilización.

Preparación de la suspensión de conidios: La suspensión se preparó para cada hongo en estudio, adicionando conidios a $50 \mathrm{ml}$ de solución fisio- lógica y $0,05 \mathrm{ml}$ de tween 80 , hasta alcanzar una densidad óptica de 0,250 , que equivale a $2 \times 106$ conidios $/ \mathrm{mL}$, para una longitud de onda de $560 \mathrm{~nm}$.

Materia Prima: Papa variedad SPUNTA de descarte se usó como sustrato, es una variedad holandesa, que se obtuvo de la zona de pie de montaña de Concepción (Tucumán), Argentina.

Medio de Fermentación: El medio de hidrolizado de papa se preparó de la siguiente manera: se pesó $200 \mathrm{~g}$ de papa variedad Spunta de descarte, la cual se picó y se agregó a $900 \mathrm{ml}$ de una solución que contiene, en $\mathrm{g} / \mathrm{L}: \mathrm{KH}_{2} \mathrm{PO}_{4} 1,0 ; \mathrm{NaNO}_{3} 3,0$; $\mathrm{MgSO}_{4} \cdot 7 \mathrm{H}_{2} \mathrm{O} 0,5, \mathrm{y} \mathrm{CaCl}_{2} 2,0$, a pH 4,0. Se licuó hasta homogeneidad ( $5 \mathrm{~min}$ ) y posteriormente el medio se esterilizó a $121^{\circ} \mathrm{C}$ durante $10 \mathrm{~min}$.

Proceso fermentativo: Los ensayos se realizaron por un proceso en lote con sistema de cultivo sumergido y fueron incubados en agitador rotatorio a $25^{\circ} \mathrm{C}$ a $250 \mathrm{revol} / \mathrm{min}$ durante $120 \mathrm{~h}$. Las muestras se tomaron cada $24 \mathrm{~h}$ de incubación para su posterior análisis enzimático.

II. Influencia de pH y temperatura sobre la actividad de los extractos enzimáticos fúngicos Obtención de los extractos enzimáticos: La biomasa del hongo se separó por filtración y el caldo fermentado (Extracto crudo enzimático) fue precipitado con (NH4) $\mathrm{SO}_{4}$ al 20 y posteriormente al $60 \%$ de saturación. Los mismos fueron dializados durante $12 \mathrm{~h}$ en tampón ácido acético-acetato de sodio $(0,1 \mathrm{~N})$ a $\mathrm{pH} 4,5$ y a $5{ }^{\circ} \mathrm{C}$, para eliminar la sal. Posteriormente fueron mantenidos a $4{ }^{\circ} \mathrm{C}$ hasta determinación de actividad amilásica.

Influencia del pH y temperatura sobre la actividad enzimática: Los ensayos para los extractos enzimáticos, parcialmente purificados de cada hongo, se realizaron de la siguiente manera. Se tomó $0,05 \mathrm{~mL}$ del extracto enzimático (parcialmente purificado) y se colocó en tubos de ensayo, luego se agregó $0,20 \mathrm{~mL}$ de la solución de tampón ácido acético-acetato de sodio, $(0,1 \mathrm{~N})$ a diferentes $\mathrm{pH}$ : 2,$5 ; 3,5 ; 4,0 ; 4,5 ; 5,0$ y 5,5 y para $\mathrm{pH}$ básicos: 6,0 , 7,0 y 8,0 se usó tampón fosfato de sodio monobá- 
sico y dibásico $(0,1 \mathrm{~N})$. Posteriormente, se agregó, a cada tubo, 0,25 mL de solución de almidón soluble $(0,1 \%)$. Cada ensayo de $\mathrm{pH}$ se incubó a las siguientes temperaturas: $20 ; 25 ; 30 ; 35$ y $40^{\circ} \mathrm{C}$.

\section{Análisis cualitativo de las enzimas del com- plejo amilásico del hongo seleccionado:}

A fin de determinar cualitativamente las enzimas amiláceas que genera el hongo altamente productor, se realizó el siguiente ensayo:

a) Se cultivó el hongo en el medio de hidrolizado de papa durante $72 \mathrm{~h}$. El cultivo se filtró por papel de filtro, y el filtrado obtenido (extracto crudo enzimático) se usó para este ensayo. Los experimentos se realizaron por duplicado y en dos experimentos separados: b) Se prepararon soluciones estándar de los siguientes azúcares: maltosa, dextrinas, almidón puro y almidón soluble, al 0,05\%. Cada una se llevó a pH 4,0, se adicionó 2,0 g de agar y se llevó a un volumen de $100 \mathrm{ml}$. Posteriormente se calentó a $100^{\circ} \mathrm{C}$ por $10 \mathrm{~min}$, para solubilizar el agar. c) En las cajas de Petri que contienen la solución de azúcar agarizada, se realizaron orificios de $5 \mathrm{~mm}$ y se agregó un volumen de $0,03 \mathrm{~mL}$ del extracto crudo enzimático de diferentes tiempos de incubación (24; 48 y 72 h). Las cajas se llevaron a incubar a $35^{\circ} \mathrm{C}$ durante $24 \mathrm{~h}$. La aparición de halos de hidrólisis se reveló con una solución de $\mathrm{I}_{2}-\mathrm{KI}\left[\mathrm{I}_{2}\right.$ $(0,026 \%)+\mathrm{KI}(0,26 \%)]$.

\section{Determinaciones}

Masa celular o biomasa: La masa fúngica se separó del caldo fermentado (extracto enzimático) por filtración usando papel de filtro Whatman $\mathrm{N}^{\circ} 1$. El micelio se lavó 2 veces, con agua destilada, y se colocó en pesafiltro previamente tarado. Posteriormente se secó en estufa a $105^{\circ} \mathrm{C}$, hasta peso constante. El crecimiento celular se expresó en gramos peso seco / litro de medio (g.p.s /L.).

Análisis cuantitativo de Actividad Amilásica: La actividad amilásica se determinó de acuerdo a Álvarez et al. (2011) (18). La mezcla de reacción contiene: $0,25 \mathrm{ml}$ de solución de almidón soluble $(0,1 \%)$ disuelto en tampón acetato $(0,2 \mathrm{M}$; $\mathrm{pH} 4,0)$; $0,15 \mathrm{ml}$ de agua destilada y $0,10 \mathrm{ml}$ del extracto crudo enzimático. Posteriormente las mezclas se incubaron a $35{ }^{\circ} \mathrm{C}$ por $30 \mathrm{~min}$. Paralelamente a la mezcla de reacción, se realizaron blancos de enzima $(0,10 \mathrm{ml}$ de extracto crudo enzimático y 0,40 $\mathrm{ml}$ de tampón acetato $(0,2 \mathrm{M})$ a $\mathrm{pH} 4,0)$; y de sustrato $(0,25 \mathrm{ml}$ de solución de almidón soluble al $0,1 \%$ y $0,25 \mathrm{ml}$ de tampón acetato $(0,2 \mathrm{M})$ a $\mathrm{pH}$ 4,0 . Estos recibieron el mismo procedimiento que las mezclas de reacción. Los azúcares liberados por acción enzimática fueron determinados utilizando una curva patrón de glucosa (19). Una Unidad Amilásica se define como la cantidad de enzima que cataliza la liberación de 1 umol de azúcares reductores, expresados como glucosa, por minuto, a $\mathrm{pH} 4,0$ y a $35^{\circ} \mathrm{C}$.

Actividad relativa, es la actividad obtenida y referida a la máxima actividad encontrada y se calcula de acuerdo a la siguiente ecuación: Actividad obtenida $\mathrm{x}$ 100/ Actividad máxima $=(\%)$

\section{Parámetros matemáticos}

Coeficiente de rendimiento de producto respecto al sustrato $\left(\mathrm{Y}_{\mathrm{p} / \mathrm{s}}\right)$ : Se define como producto formado (Unidades de enzima) en base a sustrato inicial y se calcula por la siguiente ecuación: $\mathrm{Y}_{\mathrm{p} / \mathrm{s}}$ $=($ Unidades de enzima $/$ Almidón inicial $)=\mathrm{U} / \mathrm{g}$.

Coeficiente de rendimiento de producto respecto a la biomasa formada $\left(\mathrm{Y}_{\mathrm{p} / \mathrm{x}}\right)$ : se define como producto formado (Unidades de enzima) en base a masa fúngica producida (peso seco), de acuerdo a la ecuación: $\mathrm{Y}_{\mathrm{p} / \mathrm{x}}=$ (Unidades de enzima /masa fúngica) $=U / g$.

Reproducibilidad de los resultados: Todos los experimentos se realizaron por duplicado y en ensayos separados. Los valores son el promedio de dos mediciones. Los mismos se analizaron para obtener la desviación estándar con un MS-Excel y calculados para $\mathrm{F}=95 \%$ (grado de confianza). 


\section{RESULTADOS}

\section{Selección del hongo con alta producción de amilasa.}

En la figura 1 se observa que los microorganismos mayores productores de amilasa fueron, A. niger; A. flavus; A. fumigatus A. ochraceus y A. nidulans.

\section{Influencia de pH y temperatura sobre la acti-} vidad de los extractos enzimáticos fúngicos.

Con los extractos enzimáticos parcialmente purificados, de $A$. niger; A. flavus; $A$. fumigatus $A$. ochraceus y $A$. nidulans, se estudió el rango de $\mathrm{pH}$ en el cual se obtiene elevada actividad amilásica. En la figura 2 se observa que de los hongos empleados la mayor actividad amilásica, fue con $A$. niger, que aún tiene un $80 \%$ de actividad a pH 8,0.

En la Tabla 1 se muestra que la actividad amilásica de $A$. niger no fue afectada a las temperaturas ensayadas manteniendo un valor superior al $80 \%$ a $40^{\circ} \mathrm{C}$ en condiciones extremas de $\mathrm{pH}(\mathrm{pH}$ $8,0)$.

\section{Análisis cualitativo de las enzimas amiláseas del hongo seleccionado:}

En la figura 3 se muestra el análisis cualitativo de las enzimas amiláseas de $A$. niger. En todos los azúcares ensayados, se observa que con los extractos crudos enzimáticos de las $48 \mathrm{~h}$ de incubación, los halos de hidrólisis obtenidos son mayores con almidón (C) y almidón soluble (D) que a otros tiempos, revelando un aumento de la concentración de enzimas amiláseas. Mientras que, con dextrina (A) y maltosa (B), se obtienen halos de mayor hidrólisis posiblemente por ser azúcares más simples que los polisacáridos utilizados. Los halos mostrados en maltosa (figura 3-B), sugieren la presencia de glucoamilasa, este resultado fue confirmado cuando al hongo se lo cultivó en medios con maltosa, donde fue detectada actividad glucoamilasa extracelular pero no de $\alpha$-amilasa.
Tabla 1. Efecto de la temperatura sobre la actividad amilásica en los extractos enzimáticos de $A$. niger. Los Ensayos se realizaron a $\mathrm{pH} 8,0$ y son valores promedio de dos reacciones enzimáticas por duplicado.

\begin{tabular}{cl}
\hline $\begin{array}{c}\text { Temperatura } \\
\left({ }^{\circ} \mathrm{C}\right)\end{array}$ & $\begin{array}{c}\text { Actividad } \\
\text { relativa } \\
(\%)\end{array}$ \\
\hline $\mathbf{2 0}$ & 80 \\
$\mathbf{2 5}$ & 80 \\
$\mathbf{3 0}$ & 95 \\
$\mathbf{3 5}$ & 85 \\
$\mathbf{4 0}$ & 80 \\
\hline \multicolumn{2}{c}{ DISCUSIÓN }
\end{tabular}

\section{Selección del hongo con alta producción de amilasa}

En la figura 1, se muestra que de los microorganismos estudiados la mayor concentración de enzimas (128 U/L) fue con A. niger; con mejores rendimientos de producto $\left(\mathrm{Y}_{\mathrm{p} / \mathrm{x}}=18,3 \mathrm{U} / \mathrm{g}\right)$ y productividad $(\mathrm{Pdv}=2,7 \mathrm{U} / \mathrm{hL})$; disminuyendo ligeramente con A. flavus; A. fumigatus A. ochraceus y $A$. nidulans, a las $48 \mathrm{~h}$ de incubación. Mientras que la producción de enzima fue un 73; 61 y $49 \%$ menor con P. expansum; P. islandicum; y Geotrichum candidum, respecto a la obtenida con $A$. niger, en las condiciones de cultivo empleadas $\left(25^{\circ} \mathrm{C}\right.$ y pH 4,0$)$. Los bajos valores obtenidos con aquellos hongos coinciden con los reportados para la producción de enzima por Aspergillus oryzae MTCC 317, la cual disminuyó un $44,4 \%$, cuando la temperatura fue menor a $30^{\circ} \mathrm{C}(20)$. Mientras que, la producción de amilasas en hongos termófilos, como Talaromyces emersonii y Thermomyces lanuginosus, respectivamente, fue a 50 y $55^{\circ} \mathrm{C}$ $(21,22)$. Estos resultados no son redituables a nivel industrial, considerando que se requiere para la producción un costo adicional para la energía de calefacción. 


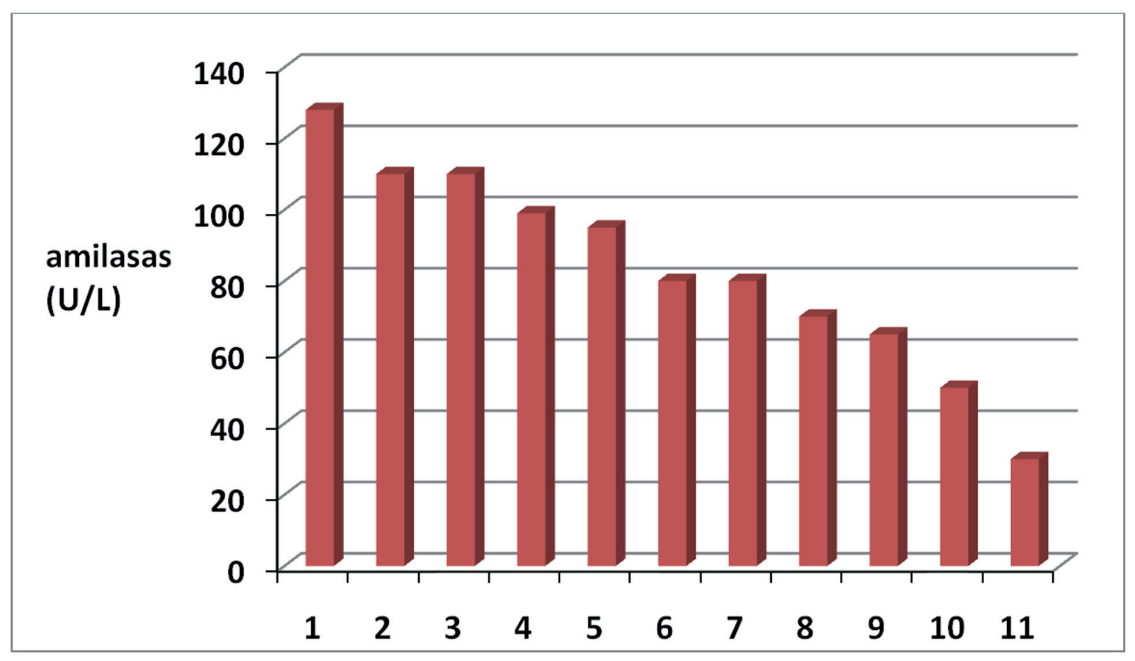

Figura 1: Concentración de amilasa en medio de hidrolizado de papa de descarte por los siguientes hongos: 1-Aspergillus niger; 2-Aspergillus fumigatus; 3-Aspergillus flavus; 4- Aspergillus ochraceus; 5-Aspergillus nidulans; 6-Aspergillus clavatus; 7-Aspergillus oryzae; 8-Penicillium digitatum; 9-Geotrichum candidum; 10-Penicillium islandicum; 11-Penicillium expansum. Los valores fueron obtenidos a las $48 \mathrm{~h}$ de incubación y son promedio de dos experimentos realizados por duplicado con $\mathrm{F}=95 \%$.

Al pH utilizado $(\mathrm{pH} 4,0)$, nuestros resultados muestran que la producción de amilasas por $A$. niger en estudio, tiene carácter mayormente ácido $(\mathrm{pH}=4,0)$, similarmente al encontrado $(\mathrm{pH}=5,0)$ para la producción de amilasas de Aspergillus sp. (23). Por el contrario, la producción de éstas enzimas por A. oryzae SR2 y Penicillium commune mostraron óptimos a $\mathrm{pH} 7,0$ y 6,0 , respectivamente $(24,25)$.

\section{Influencia de $\mathrm{pH}$ y temperatura sobre la acti- vidad de los extractos enzimáticos fúngicos.}

Un factor importante sobre el crecimiento y las actividades enzimáticas es el $\mathrm{pH}$. Esto se debe a que, al modificar la acidez del medio, se puede producir alteraciones iónicas de la pared celular; membrana celular y/o el en el mismo sustrato, incidiendo de alguna manera sobre la síntesis de las enzimas y/o actividad enzimática (25). En la figura 2 se observa que los valores de $\mathrm{pH}$ ácido tienen un importante efecto en la disminución de la actividad de las enzimas de los hongos empleados, siendo considerable a $\mathrm{pH}$ mayor a 5,5. El efecto sobre la actividad del extracto enzimático de $A$. niger es menor, mostrando un $80 \%$ de actividad, a $\mathrm{pH} 8,0$; este resultado es importante porque la enzima tiene actividad en un rango amplio de $\mathrm{pH}$, lo cual permite ser aplicada en biodertergente, que generalmente tienen un $\mathrm{pH}$ alcalino. Aunque el $\mathrm{pH}$ óptimo de actividad de las amilasas microbianas varía entre 2,0 a 12, en algunos microorganismos, la producción se encuentra en un rango ácido a neutro (21). Otro parámetro es la temperatura de incubación, la cual no solo influye sobre el crecimiento del microorganismo sino también sobre sus actividades biológicas, y es uno de los factores que deben ser optimizados. En la Tabla 1, se muestra que con los extractos enzimáticos de $A$. niger, a las temperaturas de frecuente lavado $\left(25\right.$ y $\left.30{ }^{\circ} \mathrm{C}\right)$ no se produjo marcada disminución de la actividad enzimática, mostrando un $80 \%$ de actividad a $40^{\circ} \mathrm{C}$. En conclusión, de los hongos empleados, $A$. niger fue el de mayor producción de enzima, las cuales exhiben características eficientes para ser empleadas en la remoción de manchas amiláceas de tejidos en el rango de $\mathrm{pH}$ de ácido - alcalino $(\mathrm{pH}$ $2,5-8,0)$ y a la temperatura ensayada $\left(25^{\circ} \mathrm{C}\right)$. 


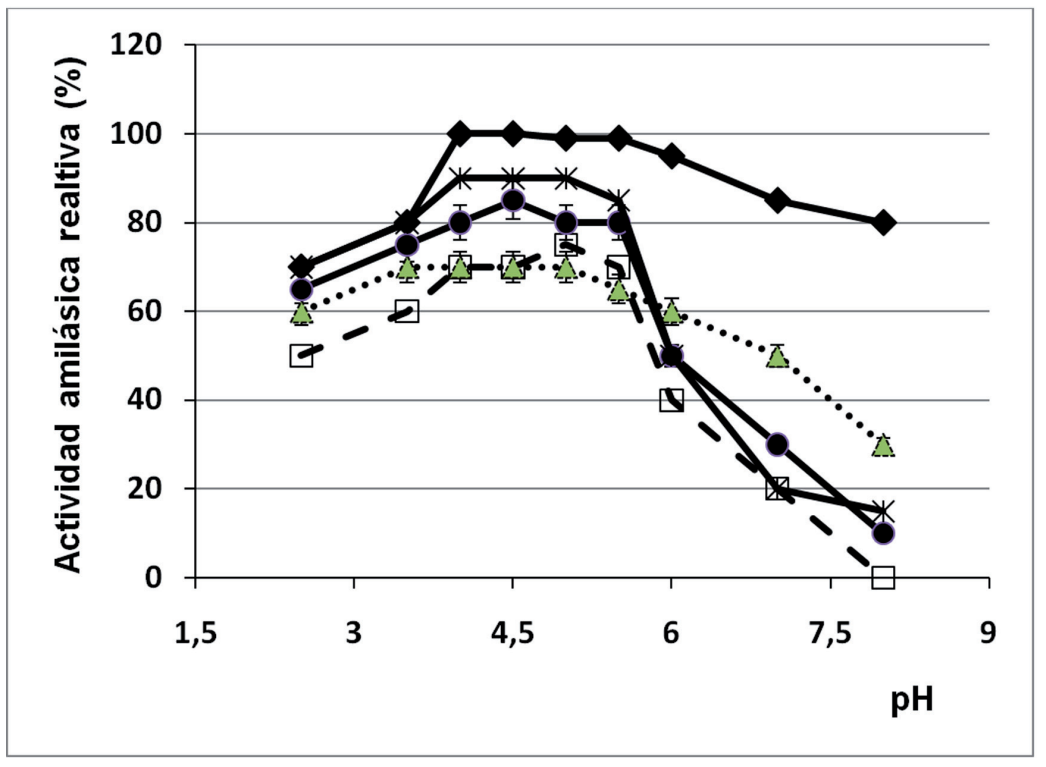

Figura 2. Efecto del $\mathrm{pH}$ sobre la actividad amilásica, expresada como actividad relativa (\%), de los extractos enzimáticos de los siguientes hongos: $A$. niger (- $\downarrow)$; A. flavus (-Х-); A. fumigatus (-๑-); A. nidulans (- $\Delta$-); A. ochraceus $(-\square-)$. Las mezclas de reacción fueron incubadas a $25^{\circ} \mathrm{C}$ y son valores promedio de dos reacciones enzimáticas por duplicado con $\mathrm{F}=95 \%$.

Figura 3. Actividad amilásica de enzimas producidas por $A$. $n i-$ ger. Solución agarizada con: A) dextrina; B) maltosa; C) almidón puro y D) almidón soluble. En cada orificio se agregó un volumen de $0,03 \mathrm{~mL}$ de extracto crudo enzimático, de distintos tiempos de incubación: 0 ; 24; 48 y $72 \mathrm{~h}$, obtenidos del proceso fermentativo.

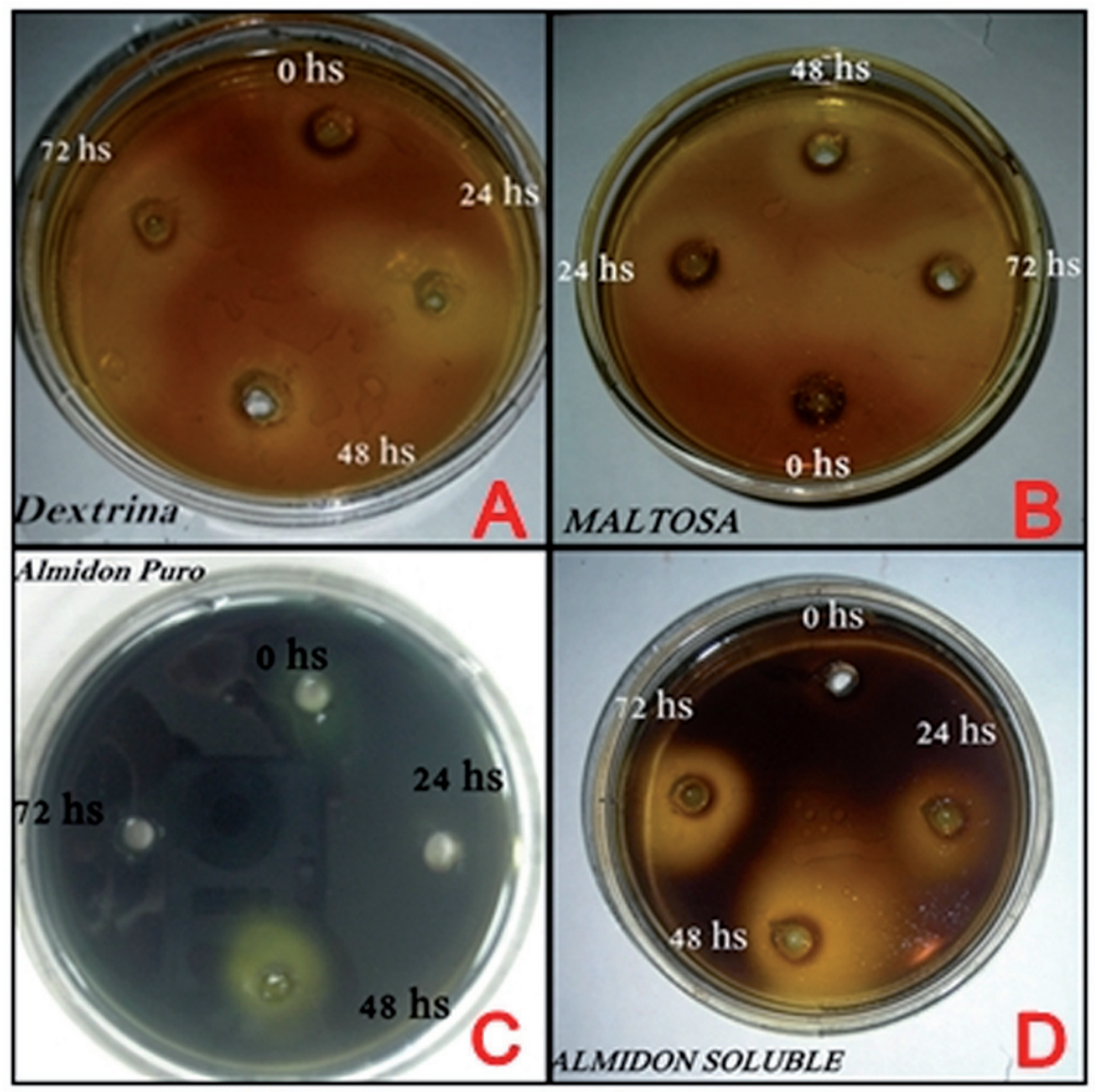

\section{AGRADECIMIENTOS}

Se agradece a la Universidad nacional de Tucumán y al centro de Investigación de la UNT. 
SELECCIÓN DE UN HONGO FILAMENTOSO ALTAMENTE PRODUCTOR DE AMILASAS - Vargas M. et al

\section{REFERENCIAS}

1. Adinarayama, K.; Suren, S. (2005). Response surface optimization of enzymatic hydrolysis of maize starch for higher glucose production. Biochem. Eng. J. 27:179-190.

2. Hyun, J. Ch; Liu, Q (2009). Impact of molecular structure of amylopectin and amylase on amylase chain. Association during cooling. Carbon polym. 77:807-815.

3. Pornpong, S.; Saoranee, D.; Sihwat, L. (2005). Effect of glycation on stability and kinetic parameter of thermostable stability and kinetic parameter of glucoamylase from A. niger. Proc. Biochem. 40:2821-2826.

4. Ahmadzadeh G. R.; Ghiafeh, M. (2011). Evaluation of changes in phytase, $\alpha$ - Amylase and protease activities of some legume seeds during germination. Int. Conferen. Biosc. Biochem. Bioinform. 5: 353-356.

5. Raimi, O.G.; Olaitan, S.N.; Fajana, O.O. y Sanni, J.O. (2012). Effect of germination time on fat and protein contents, and $\alpha$-amylase. Pakistan $\mathrm{j}$. Food Sc, 23:86-89.

6. Gacesa, P.; Hubble, J. (1990). Tecnología de las enzimas. Editorial Acribia, Zaragoza-España p. 111.

7. Roohi, M.K (2013) Cold-active detergent-stable extracellular $\alpha$-amylase from Bacillus cereus GA 6: Biochemical characteristic and its perspectives in laundry detergent formulation. J. Biochem. Tech. 4: 636-644-.

8. Bunke, D.; Jager, I; Holter, N. (2003). Environmental optimization in textile finishing. Melliand Int. Textile Report. 84:79-80.

9. Tripathi P.; Leggio, L.; Mansfeld, J; UlbrichHofmann, R.; Kayastha, A. (2007). Alpha- amylase of mung bean (vigna radiata) correlation of biochemical properties and terciary structure by homology modelin. Phytochem. 68:1623-1631.

10. Santa María, M.; Chou, C.; Yencho, G.; Haigler, C.; Thompson, W.; Kelly, R.; Sosinsk, B. (2009). Plan cell calcium-rich environment enlances thermostability of recombinantly produced $\alpha$ amylase from the hyperthermophilic bacterium thermotoga maritime. Biotech. Bioeng 104:5-7.

11. Rohleder N.; Lobos J.M.; Maldonado, E. (2006). El aumento inducido por el estrés psicosocial en la $\alpha$ amilasa salival independiente de flujo salival. Psicofisiolog.: 43:645-662.

12. Akcan, N.; Uyar, F.; Guven, A. (2011). Alphaamylase production by Bacillus subtilis RSKK96 in submerged cultivation, Kafkas Univ. Vet. Fak., 17:17-22.

13. Navarro, D.; Rodriguez, A. (2009). Modificación funcional de glucoamilasa de Saccharomyces cerevisiae. Mol. Enz. 10:39-45.

14. Francis, F.; Sabu, A.; Nampoothiri, K.M.; Ramachandran, S.; Ghosh, S.; Szakacs, G.; Pandey, A. (2003). Use of response surface methodology for optimizing process parameters for the production of $\alpha$-amylase by Aspergillus oryzae. Biochem. Eng. J. 15:107-115.

15. Gupta A.; Gupta V.; Modi D.; Yadava L. (2008). Production and characterization of $\alpha$-amylase from Aspergillus niger. Biotechnol; 7:551-56.

16. Vargas Corbalán M. \& Rubio, M. C. (2014) Producción de amilasas por Aspergillus niger utilizando como sustrato papa (Solanum tuberosum) de descarte: Recuperación de un residuo proteico para alimento animal. Tesis para optar al grado de Licenciado en Biotecnología. Facultad de Bioqui- 
mica, Química y Farmacia.UNT.

17. Mohandas, B.; Prabhakar, A.; Rao, R.; Madhu, G. (2010). Optimization of process variables for amylase production using agro residual wastes by taguchi methodology. Chem. Proc. Model.5:32.

18. Alvarez H.; Morgenfeld, F.; Perez M.; Castro, C.; Wirth S. (2011). Conceptos y Técnicas de Biotecnología I Departamento de Fisiología, Biología Molecular y Celular Facultad de Ciencias Exactas y Naturales. Guía Trabajos Prácticos. Universidad de Buenos Aires, p. 1-4.

19. Somogyi N.A. (1945). A new reagent for the determination of sugar. J. Biol. Chem. 160:61-63.

20. Puri, S.; Arora, M.; Loueleen, S. (2013). Production and optimitazion of amylase and glucoamylase using Aspergillus oryzaeunder solid state fermentation. Proc. Biochem. 3: 83-88.

21. Bunni, L.; Mc Hale, L.; Mc Hale, A. (1989). Production, isolation and partial characterizacion of an amylase system produced by Talaromyces emersonii. CBS 814.70. Enz. Microb. Technol. 11:370-375.

22. Sivaramakrishnan, S.; Gangadharan, D.; Mampoothiri, K.; Soccol, R.; Pandey, A. (2006). $\alpha$ - amylase from microbial sources - An overview on recent developments. Food Technol. Biotech. 44:173-184.

23. Chimata, M.; Sasdhar; P.; Challa, S. (2010). Production of extracelular amylase from agricultural residue by a newly Aspergillus species in solid state fermentation. Afr. J. Biotechnol. 9: 51625169.

24. Irfan, M; Nadeem, M.; Syed, Q. (2012). Media optimization for amylase production in solid state fermentation of wheat bran by fungal strains. J. Cell. Mol. Biol. 10:55-64.

25. George, U.; Tasie, F.; Anyamene, N. (2013). Studies on low-cost substrates and other cultural conditions for optimal amylase yield from Aspergillus orizae- SR2. Am. J. Foof Technol. ISSN 1557-4571/DOI: 10.3923, P. 1-10. 